\title{
UM OLHAR SOBRE A EDUCAÇÃO NO PRIMEIRO ESTADO AFRO-AMERÍNDIO DA AMÉRICA: O HAITI
}

\author{
R. PROSPERE*, E. BERGAMO, C. BATTESTIN e A. NOGARO \\ Universidade Regional Integrada do Alto Uruguai e das Missões \\ rentinp@hotmail.com*
}

Artigo submetido em JULHO/2015 e aceito em JULHO/2016

DOI: $10.15628 /$ holos.2016.3222

\section{RESUMO}

O presente artigo tem como objetivo principal, abordar os principais problemas educacionais vividos por longas décadas no Haiti à luz da análise e investigação bibliográfica. Neste trabalho, partimos com a reflexão em torno do exemplo da incansável luta que rompeu com o com o sistema escravagista no ano de 1804 e o país tornou-se a primeira República Negra livre no mundo. Entretanto, até o presente momento, infelizmente não conseguiu erguer um sistema educativo capaz de dar respaldo ao mais simples problemas de educação deste país. Acreditamos que, os possíveis caminhos para a mudança no campo da Educação deve partir dos pressupostos éticos-morais voltados para a valorização e transformação da sociedade haitiana como um todo. Com base nessa perspectiva, é fundamental o papel do educador frente aos problemas educacionais do Haiti; uma vez que o educador poderá ser protagonista, capaz de apresentar e articular ideias, propostas e alternativas para transformar a realidade vivida, na coletividade através da ação e reflexão sobre as causas. 0 artigo se termina propondo uma possibilidade de alternativa de educação, e também aponta para a necessidade do comprometimento de chamar todos os concidadãos, sejam eles que residem na diáspora ou não, a contribuirse com a qualidade da educação. Assim, poderemos esperar um Haiti livre, soberano, solidário, sem miséria, ou seja, um Haiti próspero onde haja lugar para a educação possa ser uma ferramenta indispensável para a transformação desta sociedade.

PALAVRAS-CHAVE: Haiti. Educação, Cultura. Resistência. Alternativas

\section{A LOOK AT EDUCATION IN THEFIRSTAFRO-AMERINDIANSTATEOF AMERICA: HAITI}

\begin{abstract}
The main objective of this paper is to address the main educational problems experienced in Haiti through decades under the light of bibliographic research and analysis. This paper starts with are flectionar ound the example of tireless struggle that broke with the slavery system in the year 1804 and the country became the first free Black Republic in the world. However, until now, unfortunately, it could not lift an educational system capable of giving support to the simpler problems of education in the country. It is believed that the possible ways for changes in the field of education from the ethical-moral assumptions for the recovery and transformation of Haitian society as a whole. Based on
\end{abstract}

this perspective, it is essential that the role of the educator in front of Haiti educational problems; once the educator can be protagonist, able to present and articulate ideas, proposals and alternatives to transform reality, in the collective through the action and reflection on the causes. The article ends by proposing a possibility of alternative education, and points to the need for commitment to call all citizens, whe ther they are residing in the diaspora or not, to contribute for the quality of education. So, a free Haiti can be expected, sovereign, solidarity, misery free, a prosperous Haiti where there is a place for education can be an indispensable tool to transform this society.

KEYWORDS: Haiti. Education. Resistance. Alternatives. 


\section{APRESENTAÇÃO}

Abordar a questão de Educação do/no Haiti, conhecido como a Primeira República Negra no mundo que rompeu com o sistema escravagista e colonialismo Francês no ano de 1804, é extremamente complexo. Compreendemos que todo sistema educativo forma um bloco com sistema político, onde muitas vezes seus atores são conscientes ou não de suas funções e suas responsabilidades. Neste caso, no Haiti se faz um desvio de teoria. De fato, os primeiros dirigentes do país não chegaram a definir um plano educativo e nem a construir um sistema político viável, nem nos casos mais simples. Sabemos também, que existem vários fatores que contribuem para o fracasso do sistema educativo do/no Haiti que talvez neste trabalho, não teria espaço suficiente para mencionar todos na parte introdutória.

Destacamos que, no contexto atual, o impulso que leva o homem em busca de uma educação é quase um processo ontológico, ou seja, esse processo faz parte de sua própria natureza de sentir-se como um ser incluso, em constante construção, por isso podemos encontrar várias definições a respeito desse conceito, começando com o mais conhecido apresentado pelo dicionário Aurélio (2011) na qual define a educação como processo de desenvolvimento da capacidade física, mental e moral da criança e do ser humano em geral, que visa à sua integração individual e social. É definido também como os conhecimentos ou as aptidões resultantes de tal processo e em relação ao cabedal cientifico e os métodos empregados na obtenção de tais resultados. Por fim, o conceito aparece também como aperfeiçoamento integral de todas as faculdades humanas e como conhecimento e prática dos usos da sociedade.

Em contrapartida, temos no dicionário de filosofia, a seguinte explicação sobre o termo educação:

Em geral, designa-se com esse termo transmissão e o aprendizado das técnicas culturais, que são as técnicas de uso, de produção, de comportamento, mediante as quais um grupo de homens é capaz de satisfazer suas necessidades, protegerse contra a hostilidade do ambiente físico e biológico e de trabalhar em conjunto, de modo mais ou menos ordenado e pacífico. As modalidades ou formas de realizar ou garantir essa transmissão chama-se educação. Portanto, há duas formas fundamentais de educação, 1) a que simplesmente se propõe a transmitir as técnicas de trabalho e de comportamento que já estão em poder do grupo social e garantir a sua relativa imutabilidade; 2 ) a que, através da transmissão das técnicas já em poder da sociedade, se propõe formar nos indivíduos a capacidade de corrigir e aperfeiçoar essas mesmas técnicas.(ABBAGNANO, 2000 p.305-306)

$\mathrm{Na}$ nossa compreensão, as definições de educação do dicionário Aurélio são completamente diferentes do dicionário de filosofia, ou seja, no primeiro não está presente a palavra "cultura", na qual encontramos no dicionário de filosofia como o elemento central na educação. Por esta via, acreditamos que as referidas técnicas culturais, quando são transmitidas, pois só poderão ser chamadas de "educação", se forem feitas de forma coletiva e harmoniosa inclusive, devem estar em constante transformação, para que possam corrigir erros do passado e apontar sempre para um futuro melhor.

Na visão de José E. Ramão (2008), a educação é a práxis, ou seja, é a influência mútua entre a teoria e a prática. A educação, muitas vezes, chega a ser definida como transmissora de conhecimentos, costumes, etc. Nesse caso, educação e cultura cruzam-se entre si; e desse modo, 
o ser humano humaniza-se ao compartilhar a cultura de mundo no qual se insere. Portanto, educação deve ser entendida também como um ato político e integrador, ou nas palavras de Freire, "ninguém educa ninguém, como tampouco ninguém se educa a si mesmo: os homens se educam em comunhão, mediatizados pelo mundo" (2008, p. 151).

Nesse sentido, é oportuno ter sempre presente onde se originou a educação e o modo como a mesma foi transitando de uma esfera a outra:

A educação, de um obscuro domínio da esfera doméstica, tornou-se, progressivamente, um tema central nos debates sobre as políticas nacional e internacional. Essa passagem da educação da esfera doméstica para a esfera pública, com a centralidade que lhe é atribuída nos processos de desenvolvimento humano, coloca problemas complexos ao estudo das políticas educacionais.(TEODORO, 2003, p.17)

Se pensarmos que outro mundo é possível, necessário e impostergável, teremos de acreditar que, uma outra educação é também possível, necessária e impostergável. Não podemos edificar um outro mundo possível com a educação que temos, porque, com essa mesma educação, geramos processos a serviço de um mundo excludente, construído por nós mesmos. Essa educação levará o indivíduo a uma criticidade que vai além do simples olhar. Um olhar crítico desbravador das entranhas da realidade que, às vezes, o próprio sistema nos coloca como algo imutável.

\section{EDUCAÇÃO E DESENVOLVIMENTO ESTÃO EM CAMINHOS PARALELOS DO/NO HAITI}

Podemos afirmar com parcialidade que, pelo menos no ocidente, todo sistema educativo forma um "bloco" com o sistema político, ou seja, um precisa do outro para poder existir, dependendo da visão e da estrutura na qual os atores estão envolvidos. Entretanto, no caso do Haiti, cabe perguntar se: Os primeiros dirigentes chegaram a definir um plano, ou um projeto pedagógico viável que poderia dar respaldo a todos os problemas que o país vem atravessando fortemente nas últimas décadas? Sabemos que é uma pergunta extremamente complexa a ser respondida, visto que, essa resposta necessitará de uma análise mais aprofundada acerca da esfera política, econômica, social e educativa. Assim, esperamos encontrar alguns teóricos principalmente do Haiti ou preocupados comum a temática, para que possamos chegar ao entendimento melhor desse enigma que é tão importante para o desenvolvimento do país.

De acordo com Mirlande Manigat (2002), a história da Educação no Haiti faz lembrar a distância que se manifesta entre os princípios e a realidade, entre a vontade de fazer e o que, finalmente, o que foi realizado. Podemos acrescentar que, há quase um século, o povo haitiano mostra-se ao mundo inteiro como um povo que, apesar da extrema pobreza na qual vive a maioria da população, consegue preocupar-se com a escolarização de seus filhos ou seja, um ato nobre diante da fragilidade da vida, que perpassa por um processo ontológico.

Segundo Aristide (2000), existe um esforço extraordinário das famílias haitianas para mandarem seus filhos à escola, mesmo assim, o sistema educativo haitiano encontra-se quase em último lugar no ranking mundial em termo de eficiência. É um investimento quase em vão nesse campo, visto que as crianças haitianas terminam o ensino fundamental dois ou três anos mais tarde do que qualquer outra criança do nosso continente. 
De acordo com Jean Amorce Dugé1, nos mostra como a educação no Haiti e desenvolvimento estão em vias ou caminhos paralelos:

Constata-se que alguma coisa parece ser realizável, no nosso país todo se pratica fora do índice de desenvolvimento. Poderíamos ter uma chance, com os pequenos projetos de desenvolvimento, de alfabetização, se o desenvolvimento humano ${ }^{2}$ do ser haitiano levasse a sério os aspectos educativos. Dessa forma, os camponeses começariam a compreender por que é tão necessário que eles sejam alfabetizados. Numa época, em cada município existia pelo menos uma escola pública, o desenvolvimento se faz fora do âmbito formal ou informal da educação. Nem os alunos, nem seus familiares estão integrados. Portanto, não se pode querer desenvolver um país e educar seu povo fora de um processo de alfabetização e escolarização bem construída. (DUGÉ, 2010, p.145)

Concordamos plenamente com o autor em relação ao fato de que não existe desenvolvimento em qualquer sociedade - seja qual for o tipo de desenvolvimento - sem passar por dois pilares: a alfabetização e a escolarização. Mas para isso, é necessária e fundamental uma integração com a cultura local. Porém, no caso do Haiti, conforme o autor, o haitiano afirma aquele que vem do meio rural e é um eterno marginalizado por causa de sua cultura, aquela que inclui sua religião ${ }^{3}$ e seu estilo de vida. Sabe-se que qualquer povo tem o direito de viver sua própria cultura com toda liberdade. No entanto, no caso do praticante do Vodu 4 no Haiti, isso se manifesta de forma contrária. O sistema em si coloca a cultura do camponês como se fosse sua própria desgraça, um atraso pela sua própria educação e pelo seu próprio desenvolvimento.

Cabe destacar que em meados dos anos setenta ocorreu, uma reforma chamada "Reforme de Bernard", e justamente dez anos depois da reforma, um grande número de educadores haitianos que residiam na África, na Europa e no Canadá, constataram a falha quase total da qualidade do sistema educativo do Haiti e sugeriram uma reforma educativa que pudesse integrar a vida dos alunos baseada segundo Aristides (2000, p.180) nos seguintes pontos:

- Desenvolver o espírito crítico a partir dos fatos que lhe rodeia;

- Ser um membro ativo em termo de responsabilidade na vida comunitária;

- Aprender a ler e a escrever na sua língua materna (Kreyòl) ${ }^{5}$, tendo o Francês como a segunda língua;

- Ter a aquisição de um mínimo suficiente de informação e de compreensão do meio físico e social no qual vive;

- Desenvolver suas capacidades cognitivas e manuais.

Conforme Aristide aponta, (2000), após quinze anos da implantação dessa reforma, constataram que a mesma não possuía um planejamento estratégico. Esses são fatos que podem

\footnotetext{
${ }^{1}$ Haitiano, professor de ensino superior, mestre em didática Du FLE au Centre d'approches vivantes des langues et des médias à l'Université Blaise Pascal na França. Autor de vários artigos sobre a literatura haitiana.

2 Aqui, a noção de desenvolvimento refere-se ao aspecto educativo. A instrução, a educação procura um certo bemestar. Ver o artigo 26 da Declaração universal dos Direitos Humanos.

${ }^{3} \mathrm{Na}$ maioria das vezes são praticantes de Vodu. O Vodu é a Religião, herdada da África Negra e especialmente das regiões fon, yoruba e bantú.

${ }^{4}$ A religião popular do povo haitiano, contém muitos elementos da cultura africana, principalmente dos povos fon Ewe da África subariana.

${ }^{5}$ É uma mescla da língua Yuriba da África com a língua do país colonizador França.
} 
ser conferidos no: Diagnostico técnico do sistema educativo haitiano ${ }^{6}$.

De acordo com Aristide (2000), o sistema educativo haitiano é organizado teoricamente de acordo com os textos em vigor e consta de um ciclo fundamental de nove anos e de um ciclo secundário de três anos, esse último correspondente ao ensino Médio no Brasil. Cabe salientar que existe também o ensino pré-escolar que não é obrigatório e o ensino técnico que acolhe os alunos a pós o sexto ano do ensino fundamental nos seus estabelecimentos. Existe também o ensino profissional (EEP) cursado pelos alunos de oitava série, ou seja, antes de entrar no ensino médio nos estabelecimentos do ensino técnico.

No caso do ensino superior, que é o responsável por receber os detentores do "bacca lauréat"- que corresponde ao ensino médio no Brasil, - os estabelecimentos formam no nível de licença ou escolas profissionais superiores que preparam para carreiras de engenheiro (faculdade da ciência), de médico (Faculdade de Medicina) e de agrônomo (faculdade de Agronomia), Escola Normais Superiores, etc. Estas faculdades e as escolas são agrupadas na Universidade do Estado de Haiti (UEH), instituição autônoma e independente,de acordo com prescritos da Constituição de 1987, e outra parte,de um setor privado que consta com cerca da metade dos efetivos do superior.

É importante lembrar que, apesar dos problemas de qualidade frequentemente evocados, a educação primária sempre se beneficiou de uma atenção específica por parte dos responsáveis políticos no Haiti. A Constituição de 1987 do país de fato destaca muito claramente o caráter prioritário desse nível de ensino. No artigo 32.3, é estipula do que "o ensino primário é obrigatório e sua não observância estará sujeita a sanções determinadas pela Lei. As necessidades clássicas, incluso aí o material didático é oferecido gratuitamente pelo Estado e colocados à disposição dos alunos em nível do ensino primário." À primeira vista, esse pode representar um quesito muito interessante; infelizmente, para quem conhece um pouco o sistema educativo haitiano, o Art. 32. 3 é tão-somente uma utopia e nunca chegou a ser uma ideia concreta (CONSTITUIÇÃO, 1987. p. 57).

\section{OS PROBLEMAS CRUCIAIS DO SECTOR EDUCATIVO DO/NO HAITI}

Quando nos inclinamos sobre a questão educativa no Haiti, estamos tentando enfrentar um cenário complexo, devido à necessidade de analisar o funcionamento das diversas instituições do país. Há inúmeras entidades que intervém no meio educativo haitiano, sem nenhuma regulamentação do Ministério Nacional de Educação para adquirir um quadro legal e operacional. Segundo Constant (2007) este tipo de funcionamento tem repercussões enormes sobre a qualidade da educação e, em especial, sobre a formação dos educadores. Contudo, a estruturação acadêmica permanece pertinente, ela codifica este meio. Do mesmo modo, quando se fala dos quatro níveis de ensino/aprendizagem em Haiti: o pré-escolar, o fundamental, o secundário e o superior. De acordo com Aristide:

Cerca de um milhão de crianças não podem freqüentar a escola, às vezes é porque os estabelecimentos não existem ou às vezes são muito afastados de suas residências, ou ainda porque os custos da escola são demasiado elevados. Apesar de um forte empurrão de escolarização entre 1980 e 1998, a cobertura das

${ }^{6}$ Diagnostic technique du système éducatif haitien. Ministério de Educação Nacional da Juventude e do Esporte.(MENJS, 1995) 
necessidades escolar permanece distante a ser assegurada, particularmente no meio rural onde a freqüentação fica prodigiosamente e um atraso frente ao resto do país. As desigualdades sociais produzem-se pela escola e pela maneira também acentuada antes de 1980 (2000, p.182).

Analisando a citação acima, é crucial apontar que um dos problemas do sistema educativo haitiano começou na base, talvez por falta de acesso das crianças à escola. Pode se imaginar um país com quase dez milhões de habitantes, e quase um milhão de crianças não podem ter acesso à escola? A educação em um país tão pobre como o Haiti e talvez nos demais países devem ser tratada como "política pública". Somente assim, poderemos pensar em enfrentar essas dificuldades apresentadas.

Para continuar, seria importante colocar alguns números e fazer uma repartição geográfica a fim de ajudar a elucidar melhor a problemática. Na visão de Constant (2007), a dicotomia entre professores formados e professores não formados é quase invalidada pela assimetria existente entre os dois grupos. Conforme o programa Cadre de formação dos agentes do ensino divulgado pelo Ministério da Educação e da Formação Profissional (MENFP), o Haiti conta com quase 70000 Educadores, dos quais $85 \%$ não recebeu nenhuma formação profissional e dos quais $30 \%$ possuem um nível inferior ao ano fundamental (CONSTANT, 2007, p.01).

Constant (2007) atesta que o sistema educativo privado no Haiti está em plena expansão. De acordo com o relatório do Ministério da Educação Nacional (MENC, 2004), 3.216 estabelecimentos privados abriram suas portas entre o período de 1999 a 2003, e somente 72 estabelecimentos públicos no mesmo período. O ensino privado ou rede particular contaria com 65.785 professores para 8.917 professores na rede pública.

Há uma desproporção entre as redes públicas e privadas de ensino, desproporção esta que consideramos muito grande e desigual. Embora a Constituição de 1987 no art. 32.3 destaque que o ensino fundamental em todo o país deva ser gratuito, tal ocorrência encontra-se somente no documento oficial, ou como se costuma afirmar, está apenas "no papel". O Estado Haitiano nunca se preocupou em investir massivamente no setor educativo. Dessa forma, é importante analisar o problema educativo no Haiti na sua base.

Conforme a pesquisa do relatório publicado pelo Ministério de Educação Nacional em 2001 sobre 210 estabelecimentos pré-escolares, os professores são distribuídos geograficamente da seguinte forma:

Tabela 1: 0 ensino pré-escolar.

\begin{tabular}{lc}
\hline Departamento (Estado) & Quantidade de professores \\
\hline Ouest (Capital) & 352 \\
Sul & 114 \\
Artibonite & 97 \\
Nordest & 53 \\
Nord & 55 \\
Grand'Ans & 39 \\
Sudest & 21 \\
Nippes & 28 \\
Centre & 09 \\
\hline TOTAL & 768 \\
\hline
\end{tabular}


Nível primário. o ensino primário como é chamado no Haiti, apresenta o acesso à escola da população em idade escolar, permanecendo um dos maiores desafios do setor educativo haitiano. Em 1995, menos de $25 \%$ das crianças em idade de escolarização entre 6 e11anostiveramacesso à escola primária no meio rural, com grandes disparidades em relação a todos os Estados. Sobre um conjuntode1.156.937 crianças escolarizadas no nível primário, entre 1994 e 1995, quase85\%são obrigadas a frequentar uma escola particular.Esta percentagem que é constante desde 1987 ressalta a importância do esforço empenhado pelos pais para manter seus filhos na escola. Isso mostra mais uma vez a falha do Estado haitiano em relação ao investimento na educação.

Conforme aponta Aristides (2000), em termos quantitativos, o baixo nível acadêmico e profissional do corpo docente é, hoje, constatado por todos os atores do sistema educativo do país. A grande maioria dos educadores não atinge um nível de performance que corresponde ao ciclo escolar fundamental ou ensino médio.

Nível secundário e médio: o ensino secundário correspondente a $1^{\underline{a}}$ série até a 8a série no Brasil, e está repartido ou distribuído em $79 \%$ nas zonas urbanas, versus $21 \%$ nas zonas rurais. $23 \%$ dos professores trabalham em tempo integral na zona rural.

Aristide mostra a partir da sua posição que:

O senso de 1997 mostrou que há um efetivo de 1.170 escolas secundárias. Dessa quantidade, o setor público possui somente 144 escolas, nas quais 112 delas estão nas zonas urbanas e 32 nas zonas rurais. Trata-se de um pequeno progresso, porque em 1991 o Governo Lavas criou nada mais que 38 Liceus em todo o território nacional depois de 30 anos de ditadura, cento e oitenta sete anos de independência. Durante pouco tempo desse governo, antes do golpe de Estado criaram 19 novos Liceus modernos. Sobre este lançamento, numerosas iniciativas foram tomadas pelas comunidades para abrir novas escolas (ARISTIDE, 2000, p.183-4).

Percebe-se que o setor privado continua com um enorme peso na educação básica pela sua expansão espontânea frente à demanda social da educação. Entretanto, nem sempre esse setor prima pela qualidade do ensino, mas, sim, privilegia a quantidade. Por isso, a Educação acaba sendo, em muitos casos, como um grande negócio.

Nível superior: entre os anos de 1994 e 1995, Aristides (2000, p. 185-6).aponta que o ensino superior no Haiti atingiu um efetivo de 18.000 a 20.000 alunos, nos quais 10.000 alunos tentaram uma vaga no setor público. Há somente uma Universidade Pública no Haiti - Universidade do Estado do Haiti (UEH) que é dividida em onze faculdades, escolas e institutos: 1) Escola Nacional Superior de Tecnologia; 2) Escola Nacional de Arte; 3) Escola Nacional dos Enfermeiros; 4) Faculdade de Direito; 5) Faculdade de Ciência Econômica; 6) Faculdade de Etnologia; 7) Faculdade de Ciências Humanas; 8) Faculdade de Linguística Aplicada; 9) Faculdade de Agronomia; 10) Faculdade de Odontologia e 11) Faculdade de Medicina.

Assim, é importante salientar, de acordo com o Aristides (2000), que a maioria das Universidades, tanto a pública, como a privada, funcionam em estabelecimentos precários e não têm, muitas vezes, bibliotecas e laboratórios de pesquisa adequados. Não há um corpo docente permanente, tampouco uma estrutura administrativa coerente. 
É importante frisar que, os dados apresentados acima são de mais de uma década. Neste momento há uma ligeira mudança no sistema educativo do/no Haiti. Mas, isso não quer dizer que, houve uma mudança significativa nos últimos quinze anos, a ponto de observá-la e acompanhar em todos seus aspectos.

\section{UMA POSSIBILIDADE DE EDUCAÇÃO ALTERNATIVA DO/NO HAITI}

Queremos iniciar este último item do artigo, apelando para o conceito de cidadania no contexto educativo, no intuito de analisar que tipo de possibilidade de educação alternativa estamos nos referindo. Trazer este conceito nesta análise é muito importante, porque ao decifrar a natureza da cidadania nasce segundo Cortina (2005), a dialética do "interno/externo", da necessidade de união entre os cidadãos.

Com isso, encontramos na luta, na preocupação de Frantz Fanon (1925-1961) em relação aos países do Terceiro Mundo um verdadeiro ato de cidadania, embora ele não utilize este conceito de maneira explicita nas suas obras. Mergulhando e apreciando seus textos, experimentamos que a cidadania é uma relação política entre os indivíduos. Assim, essa relação política pode desembocar na educação política, que consiste em fazer compreender a classe oprimida que, em última instância, tudo depende de suas ações e suas decisões, de seus atos de omissão ou de participação.

Dessa forma, faz-se necessário lembrar da pesquisadora Maria Eduarda Vaz Moniz dos Santos (2005) na sua obra intitulada Que Cidadania? Que Educação? Para que Cidadania? Em que Escola? Para nos brindar teoricamente com elementos acerca do termo num viés puramente pedagógico.

A cidadania é uma cultura a construir e a educação deve ser chamada para intervir nessa edificação. Assim, assevera que a "inclusão educativa" e a promoção da cidadania são condições essenciais da educação. Entretanto, para ela, a educação e a cidadania precisam uma da outra para poder existir e isso significa afirmar que elas se imbricam mutuamente. $O$ afastamento da educação relativamente à promoção da cidadania é uma das causas da atual falha de cidadania ${ }^{7}$; por isso, em sua visão, às vezes surgem outras contradições pedagógicas:

Educar pela paz e silenciar a guerra; educar para a solidariedade e fomentar o espírito competitivo; educar pela justiça e nada a esclarecer sobre as desigualdades e as discriminações; educar pela tolerância e a multiculturalidade e iludir a situação de degradação vividas pelos imigrantes africanos e do leste europeu.(PINTO, 2004, p.116 Apud, SANTOS, 2005, p. 99).

Certamente, o que o autor ressalta na citação está explicitamente presente no cotidiano do povo haitiano; por isso, acreditamos que a educação alternativa pode ser uma possibilidade de

\footnotetext{
${ }^{7}$ Sabemos que o conceito cidadania é frequentemente tematizado. Autores clássicos como Rousseau, Marx e outros tanto expuseram o conceito como críticas dirigiram à forma de uma cidadania iluminista. Hodiernamente, Pedro Demo, Norberto Bobbio, Hans-Georg Flickinger, Adela Cortina, apenas para citar alguns, teorizam sobre a questão da cidadania, apontando para a crítica que podemos fazer ao modo como o conceito foi-se restringindo à simples concessão de direitos ao cidadão por parte do Estado. Ou como uma faca de dois gumes, nas circunstâncias em que o cidadão precisa assumir, por omissão do Estado, algumas prerrogativas que ao Estado caberiam. O modo como, nesse texto, pretendo conectar educação e cidadania tem a ver com pensar a educação e a formação como instâncias de promoção de cidadania crítica em relação aos modelos que se interpõem entre nós.
} 
educação, não para formar simplesmente sujeitos passivos, mas, sim, cidadãos críticos, que possam questionar o sistema social no qual se inserem. Assim, podemos pensar em uma educação comprometida com a democracia, com a cultura, com a religião, com a economia, com a vida social e, principalmente, com a pedagogia.

Falar em investir no ser humano com a possibilidade de uma educação alternativa numa determinada sociedade, sem dúvida, não pode ser uma tarefa fácil. Aí podem ser levantadas várias indagações, tais como? Quais são as condições que devem ser designadas na busca por uma educação alternativa no Haiti? Quais são as peculiaridades que deveriam ter essa educação alternativa? E o que podemos compreender por uma educação alternativa?

Na tentativa de encontrar respostas a essas perguntas, convém ressaltar as palavras de José Mario M. Mendéz que frisa:

Mais concretamente, entendo que em nossos países (América Latina ${ }^{8}$ ) - uma educação é alternativa quando está explicita e deliberadamente orientada a reverter o modelo social excludente a partir daquilo que configurou a sociedade centro - América. Em outras palavras, é alternativa uma educação que sugere e realiza outra qualidade do tipo humano que queremos ser (alternativa antropológico)e outro mundo feito a partir da pluralidade de mundos possíveis (alternativa cosmológico). A educação, para ser alternativa, deve estar orientada, portanto, para superar todos os dinamismos monoculturais dos que forma instrumentos eficaz até o momento, para converter-se numa mediação para que seus autores-atores recuperam a palavra para animar (dar vida) a polifonia de vozes e de formas de acesso a saber que surgem da diversidade de mundos aos quais assistimos (2009, p.93).

Por seu turno, Raúl Fornet-Betancourt $(2004$, p.67) nos indica que pensar e realizar a educação de forma alternativa exige visualizar universos alternativos de saber e de convivência humana, o que implica reivindicar "o direito para descolonizar as pautas para a educação e a convivência da humanidade e para elaborar um novo contrato cultural, baseado no diálogo, na interação e no intercâmbio.

E quando nos referimos à possibilidade de uma educação alternativa, aponto para uma educação que seja capaz de eliminar a desigualdade que não é contraditória com o respeito pela diversidade, uma educação da mesma qualidade para todos, que não nos deixa insensíveis perante a injustiça social, a injustiça cultural, a injustiça ambiental onde o respeito pelo valor da equidade e da solidariedade possa potencializar essa educação.

Essa educação deve ser democrática, participativa, ativa, consciente e sistemática, com o envolvimento de toda a comunidade. Uma educação que não se centra numa organização curricular demasiado fechada sobre si mesma, que se não se fecha no interior das lógicas disciplinares, mas que busca uma estrutura curricular adequada ao exercício da cidadania. Uma educação que não restringe o universo comunitário à escola. È, enfim, uma educação que não ignora a força do diálogo e a vivência da intersubjetividade.

\footnotetext{
${ }^{8}$ Grifo nosso.
} 
Conforme revela Mendéz, embora o conceito "alternativo" no campo da educação não é novidade nos países latinos americanos, o que importa, é como se dá essa proposta numa perspectiva intercultural:

[...] creio que a educação na América Central (no Caribe ${ }^{9}$ ) pode enriquecer se for abordada sob uma perspectiva intercultural que responda à realidade multicultural, plurilíngüe e multiétnica da região e as diversas maneiras de colonialismos sofridos no passado e no presente. Assumir uma perspectiva intercultural nos permitirá - seguramente - reconhecer e valorizar a irredutível polifonia e as diversas formas de acesso ao saber, sobretudo aquela que foram historicamente negadas ou deslegitimadas por interrompidos processos de colonização política, econômica, religiosa e cultural (MENDÉZ, 2009, p.93).

Assumir essa postura numa perspectiva intercultural é ser capaz de questionar o papel conservador da escola. Sem restringir o uso das novas tecnologias ao serviço do progresso da educação. Portanto, é importante dizer que essa educação continua sendo como sempre; porém, com um olhar, uma perspectiva diferente na medida em que os valores de cada cultura e suas formas de apreciação sejam respeitadas da mesma forma. Assim, essa educação pode colocar a liberdade, a justiça, a equidade, a solidariedade, a descolonização do ensino, a democracia e o conhecimento como o centro das atenções.

Dessa forma, concordamos com Mendéz quando o mesmo frisa que:

A educação e a opressão fazem pacto quando a educação impõe verdades consideradas como universalmente válidas e inquestionáveis; quando as práticas educativas se baseiam no controle das pessoas; quando se promovem práticas de padronização curricular e metodológicas desrespeitosas das peculiaridades locais; quando existe uma obsessão pela hierarquia, a ordem, a vigilância; quando a avaliação se converte numa ferramenta para medir se a pessoa estudante sabe $o$ que o docente e o sistema educativo acreditam que deve saber; quando se educa para ser obedientes e submissos, politicamente dóceis e economicamente produtivos; quando as políticas, os projetos ou programas educativos se definem sem levar em consideração o contexto dos seres humanos concretos e históricos que participam no processo; quando se impõe uma única forma de acesso ao saber; quando desde a educação absolutizamos uma cultura - a nossa ou alheia sem sermos capazes de discernir suas tradições libertadoras e opressoras; quando se educa para a competência excludente; quando um único sistema educativo subsume em si, controla e anula todas as possíveis experiências educativas geradas desde os distintos grupos e comunidades (2009, p.94-95).

É nesse sentido, nessa direção que vislumbramos uma proposta de educação alternativa, que precisa superar todas essas ambiguidades citadas. Sem desmerecer aquela que já é implantada pelo sistema, ou seja, aquela educação que a academia denomina a certa, a mais importante, e que muitas vezes determinam os costumes ou hábitos de uma sociedade ou de uma comunidade, preocupar-se com os saberes ancestrais.

${ }^{9}$ Grifo nosso. 


\section{CONSIDERAÇÕES FINAIS}

E sendo assim, o que dizer para encerrar está análise? A temática do artigo não se encerra, ela finaliza com reflexões, anseios e esperança. Por ora, convém esclarecer que em nenhum momento pensamos em propor outra educação para o Haiti. É, entretanto, de suma importância levantar algumas reflexões acerca da educação do/no Haiti, o país mais pobre da América que, apesar das mazelas que o assolam, é capaz de descamuflar ou desvelar o que foi há muito tempo escondido no cenário internacional. Haiti é sempre visto como um país pobre e digno de solidariedade, que é, em algumas circunstâncias, obrigado a estar à mercê dos outros países. Ressaltamos, entretanto, que um dos problemas cruciais do Haiti é a educação, que nunca é levada a sério nas discussões e reflexões internacionais.

Porém, não seria justo finalizar esse artigo, sem mencionar mais uma vez que essa ilha conquistou a liberdade há mais de duzentos anos: a liberdade não Ihe foi concedida. Os haitianos combateram para tê-la. E é preciso insistir no fato de que nós a conquistamos não somente para nós mesmos, mas para todos os povos negros no mundo, porque o Haiti representa a primeira república negra no mundo, ou seja, o primeiro farol a ser acendido contra a escravidão no mundo. Vale salientar, mais uma vez, que esse acontecimento custou-lhe muito. Houve realmente momentos extremamente penosos, ao ponto de, apesar dessa liberdade conquistada, a desgraça querer que jamais os haitianos tenham podido encontrar uma organização admissível capaz de garantir uma espécie de estabilização.

É claro, os haitianos conquistaram a liberdade, o que é, evidentemente, motivo de orgulho, mas a sociedade não se transformou de modo tão profundo quanto se teria desejado. Encontra-se agora a situação em que a classe intermediária que substituiu os brancos conservou muitos hábitos (péssimos hábitos) da era colonial e não desempenharam o verdadeiro papel que aguardávamos e esperávamos. $O$ país procura sempre seu equilíbrio e infelizmente nem sempre o encontra.

Dessa forma, é imprescindível dizer que o povo haitiano é povo esperançoso e inteligente. As elites haitianas são numerosas, mas o que pode ser notado, é que houve uma grande fuga de cérebros brilhantes dessa elite durante o período da ditadura haitiana de 1957 a 1986, a maioria deles emigraram para a França, para o Canadá, e para os Estados Unidos da América. Eles permanecem no exterior e não mais encontraram seu lugar no Haiti. Acreditamos que está na hora de fazer um chamamento a essas compatriotas e colocar as mãos na massa com o intuito de reerguer o Haiti, porque levantar o país depende também - para não dizer exclusivamente - de todos os haitianos que se encontram dentro ou fora do país.

\section{REFERÊNCIAS}

1. ARISTIDE, J.B. Investir dans I’Humain. Imprimerie Henri Deschamps, Port au Prince, 2000.

2. CONSTANT, M. La convergence créole-français est-elle possible en Haïti ? In: Robert CHAUDENSON, Français et Créoles: Du partenariat à des Didactiques Adaptées. p. 127-152. OIF, I'Harmattan, 2007.

3. CONSTANT, M. La Professionalization des Enseignants de l'education de Base: les Recrutments sans Formation Inicial. I'Harmattan, 2007. 
4. CORTINA, A. Cidadãos do mundo: para uma teoria de cidadania. (Trad. Silvana C. Leite). Loyola, São Paulo, 2005.

5. DUGÉ, J.A. Éducation et Développement en Haiti: Bilan et proposition. In. SAINT-ÉLOI, R. e TROUILLOT, L. Refonder Haiti? Mémoire d’encriere: Montréal, Québec, 2010. p.143-148.

6. FANON, F. Os Condenados da Terra. Trad. Enilce Abelgaria Rocha e Lucy Magalhães - Juiz de Fora: Ed. UFJF, 2005.

7. FORNET-BETANCOURT, R. Interculturalidade: críticas, diálogos e perspectivas. Trad. Angela T. Sperb: São Leopoldo: Nova Harmonia, 2004.

8. HURBON, L. O Deus da Resistência negra: o vodu haitiana.(trad.Valdecy Tenório). São Paulo, Paulinas, 1987.

9. HAITI: Constitution, 1987. Disponível em:http://pdba.georgetown.edu/constitutions/haiti /haiti1987.html. Acessado em 08/12/08.

10. MENDEZ, J.M.M. Educação intercultural e justiça cultural. (Trad. Antonio Sidekum). São Leopoldo: Nova Harmonia, 2009.

11. RAMÃO, J.E. Educação. In. STRECK, D. ...[et al.] (orgs). Dicionário Paulo Freire. Belo Horizonte: Autêntica Editora, 2008, p.150-151

12. SANTOS, M.E.V.M. Que Cidadania? Tomo II. Santos-Edu: LISBOA, 2005.

13. SCHEINOWITZ,C. ...[et.al] (Orgs). Haiti: 200 anos de distopias, diásporas e utopias de uma nação americana. Feira de Santa: UEFS, 2004. 